\title{
A Discussion on the Current Situation and Development Strategy of Sports Associations in Colleges and Universities
}

\author{
Yanbin Li \\ College of Physical Education, Linyi University, Linyi, 276000, China
}

Keywords: Colleges and universities; Sports association; Current development status; Strategy

\begin{abstract}
There are phenomena such as disproportion of association members, singular financial resources, lack of association fund, monotonous activity contents and weak awareness of associations of college students in sports associations in colleges and universities. In order to accommodate to the rapid development of society and demands for talents in the society, constant innovation has been carried out in many colleges and universities to create new teaching philosophy and sports associations in schools have also adapted to the trend of the times to make changes both in scale and variety of associations. As the number and variety of associations increase, certain influence will be brought about accordingly, thus we must correctly deal with the building of sports associations in colleges and universities. Based on that, this paper held a discussion on the current situation and development strategy of sports associations in colleges and universities.
\end{abstract}

\section{Introduction}

Physical education has played an important role in the healthy growth of students, while physical education in colleges and universities is study for students at the final stage in their student career as well as the highest level of school physical education. Physical education in colleges and universities serves as a bond linking a student's study with practical application and plays an irreplaceable role in helping to shape the student's sports concepts after they enter the society. In the physical education in colleges and universities, in addition to routine PE teaching, sports associations should be a major organization form for sports and they have been more and more popular among contemporary college students and become an indispensable part in construction of campus culture in colleges and universities. Therefore, how to ensure the sound development of sports associations in colleges and universities and expand their coverage has become a major topic of researchers. We should constantly enrich college students' sports association activities to let them enjoy the true meaning of life from such associations and cultivate good living habits to enable them to develop into qualified talents with all-round development of morality, intelligence, physique and aesthetic. That's why this paper carried out detailed discussion and study.

\section{Development status of sports associations in colleges and universities}

\section{Insufficient attention for the sports associations with prominent discrepancy in taking in new members}

Through investigations we found that more often than not, there was very low participation of students in activity planning of sports associations in many vocational colleges. That's mainly resulted from the following reasons: firstly, the schools; in most colleges and universities, students' sports associations didn't gain enough attention and during the school just let the development of students' associations take its own course without specific guidance and encouragement and there was also no adequate publicity; secondly, it's students in vocational colleges; students didn't realize the importance of sports associations and didn't care much about improving their physical quality, thus they showed low participation in sports associations with inadequate initiative and participated such activities as a mere formality. By comprehensive analysis on the reasons above, we also found that there is another reason that resulted in a lack of attention for sports associations in colleges and 
universities, namely, prominent discrepancy in taking in new members between different sports associations. Most members of such associations were freshmen and there were few senior students participating in. Such phenomenon also brought about quite prominent hierarchy for colleges students' participation in sports activities, since only a small amount of students had enthusiasm for sports, thus it would impede students from improving their physical fitness as a whole.

\section{Lack of thorough internal management system in sports associations and insufficient development momentum}

At present, there has been no systematic or comprehensive management mechanism in sports associations in colleges and universities. Students are indifferent for sports associations established in schools and there is no effective mechanism to encourage students in charge of such associations. Also, no sufficient attention has been given to activities carried out. Thus it has greatly impeded the development of sports associations. Drawbacks in the development of sports associations are mainly manifested by the following two aspects: (1) there is no certain grading in sports associations. Most colleges and universities have no specific grading rules for estimating sports associations and treat all associations without discrimination, which will definitely affect the sustainable development of associations. Reasons for incomplete internal management mechanism of sports associations include the following: firstly, there was no elimination mechanism to select the superior and eliminate the inferior. No punishment or other means were taken for association member who ranked the last in association competitions in the association and no encouragement were given to winners, thus greatly weakening the participation enthusiasm of associations; secondly, no punishment such as degrading was given to associations that remaining the same rank in repeated evaluations; thirdly, there was a short of management authority and no power delegation was given to associations that constantly achieved good results in evaluations, thus such associations were not able to carry out normal market-oriented operation; fourthly, students who showed talents or had outstanding performance in associations were not sent to relevant sports associations to receive regular training and no sufficient attention was paid to talent outputs. (2) No professional internal management mechanism was carried out for those associations with market-oriented operation, thus impeding the development momentum of sports associations and affecting the opening up of associations. Some associations even didn't figure out their development direction and took chances when carrying out association activities to muddle through. Those could restrict the smooth developing of association activities. The main function of promoting the market-oriented operation of students' sports association is to firstly enable all association members to know about the commercialized form of sports. When schools carried out managerial work on associations, they couldn't accurately handle the prospect and direction for the development of association. Also, achievements made by associations and efforts of students in charge of associations were not recognized and advocated. Instead, they merely focused on economic benefit brought by associations and abandoned the real purpose and meaning of activities. Some colleges and universities didn't assess sponsors of association activities and didn't work out any incentive methods to reward associations that gained most sponsorship.

\section{Outdated activity contents}

Making a general survey of sports association activities in colleges and universities, we can find that most of their activity contents are outdated, which mainly include fitness and entertainment or sports competitions in stereotyped forms with a lack of innovation. Also, through investigations we learned that there were few various activities such as get-togethers, lectures and competition watching, etc. available, thus greatly affecting student's enthusiasm for participation. If association activities fall out of touch with social activities, it certainly will affect the persistent and sound development of associations and association activities will greatly reduce.

\section{Narrow communication channels of sports associations}

No matter physical education teaching or association activities in colleges and universities, they aim to improve student's ability to adapt to the society and integrate into the society as soon as 
possible. However, the fact is not the case. What we found is that there was noninterference between physical education teaching and association activities. School associations are mainly about amusement within the school with few opportunities to contact with the outside world. Just because of the narrow communication channels of associations, it will certainly restrict the sound development of associations. If we can strengthen communication and cooperation between different associations and seek common development through cooperation and learn from each other's strong points to offset their weakness, it will bring great benefit to the society to some extent. The serious lack of field and equipment in associations, lack of professional advisers and limited activity fund also more or less affected the development scope of associations. In most schools, such communications are limited to internal communications within the school like joint activities between associations to increase communication between associations, while there is few communications between schools. Such narrow communication channel will cast certain influence on the development of associations.

\section{Development strategy for sports associations in colleges and universities}

\section{Emphasis should be put on development momentum of sports associations to promote their development in an all-around way.}

For the part of vocational colleges, first and foremost, emphasis should put on development momentum of students' sports associations and enough attention should be paid to both cultivation of PE teachers and construction of sports associations to let them play their role in students' associations. Secondly, traditional ideas in taking in new sports association members and management should be changed with new ideas introduced constantly to make a scientific and reasonable use of resources and motivate students' enthusiasm for participation and promote the all-around development of sports associations.

\section{Strengthen internal management system of associations and stimulate the development vitality of sports associations}

At present, the premise for the sustainable and orderly development of sports associations is strengthening the internal management system of associations. One of the acid tests faced by sports associations is how to increase the number of new members while not losing old members. It's also a reflection of the cohesion of association culture. Thus, we should adopt effective measures and efforts as follows: (1) strengthen sports association's force in taking in new members and improve the mechanism for taking in new members. Talent first, since they are reliable guaranty to have all work done with satisfactory results. More is not better for the number of members in associations. What matters most is that all members should make concerted efforts to do a good job in sports associations. When taking in new members, attention should not be merely paid to new member's skills but their enthusiasm for sports cause, which will play a big role in association activities. (2) Enhance the market-oriented operation mechanism and create open sports associations. Through investigation, we found that most sports associations gathered within schools, while there was a lack of communication between schools. Students regarded association activities as a kind of entertainment instead of a cause. We should bring associations in touch with market to give play to their strength in the market, which will bring unexpected benefit to both the school and students. (3) Most colleges and universities merely focused on construction of sports culture such as flag of the games and slogans, while carried out few association activities. We should know that the transmission of culture should depend on certain media and the best media should be sports activities. Therefore, carrying out effective and scientific sports activities should be an important basis for developing association culture.

\section{Pay attention to the construction of sports activities}

(1) Colleges and universities should pay attention to cultural development according to characteristics of sports associations within school to constantly enrich sports association's activity 
contents. The organizers of associations should adopt different ways such as publicity to mobilize organization members' initiative and make innovations in cooperation and give play to the strength of associations in innovation. Sports associations should also constantly strengthen their team power, build good image and increase their social influence to gain uttermost support and help from both school and social organizations. (2) Colleges and universities should conform to the development trend of the times and adopt various methods to enable associations to go out of school and enrich the cultural connotation of associations, encourage and guide students to combine sports activities with social activities to manifest spirit of sports culture in social activities and communicate with enterprises to give full play to the value of sports association activities. Colleges and universities should have market in mind and integrate students' sports association activities with market demand to promote them realize the maximum benefit. Colleges and universities should also constantly develop a market mechanism that linking campus sports culture with sports commercialization to enrich students' attainment in associations through favorable resources from the society and enable students to flexibly adopt various methods to put knowledge about sports into practice and improve student' comprehensive quality in an all-around way.

\section{Increase communication channels of sports associations and create good cultural atmosphere of association}

The most effective method to reinforce association culture is to carry out external exchange mechanism. Colleges and universities should strengthen the communication channel of sports associations and create good cultural atmosphere of associations. They should guide and support associations with a broader perspective. Activities should not be limited to the campus but brought to the outside world to keep good communication and exchange with sports associations and organizations in other colleges and universities by absorbing their essence to make constant progress in such communication and promote their sound development in progress. We all know that solidarity is the footstone to overcome any difficulty in a team. Only by concerted efforts and giving play to everyone's talent can all difficulties be readily solved in a team. Thus, the leader of a sports association should adopt effective measures to motivate member's cooperative awareness, encourage them to make innovation, practice and bond personal honor and disgrace with the honor of the team. In addition, colleges and universities should also create good cultural atmosphere within the association. The so-called core of an association is exactly the concentrated expression of the spirituality and group consciousness of a team. Therefore, every member of an association should do his bit to create good cultural atmosphere of the association and serve as the host of the association, take initiative to give advices in association activities and give play to conscious activity to the maximum extent.

\section{Conclusion}

The sports associations of colleges students is a core composition of sports culture in colleges and universities, which cast great influence on promoting college students' physical and mental healthy development and creating harmonious campus. However, the least of perfection is that there are still shortcomings in the development of sports associations in Chinese colleges and universities, such as insufficient concern for sports associations, a lack of complete internal management system and narrow communication channels of sports associations, etc. In order to give play to the effectiveness of sports associations in colleges and universities, we should constantly improve and complete the existing management mode of sports associations from various aspects and make bold reform and innovation in choosing sports content and create good cultural atmosphere of associations. Colleges and universities should also strengthen the construction of sports associations to promote their sound development and contribute to the construction of campus culture. 


\section{References}

[1] Yuan Lin, Peng Guoqiang A Study on Organization and Management and Strategy for Sports Associations of College Students. Contemporary Sports, 2014, (01) :150-151.

[2] Chen Zhangyuan. Current Situation and Countermeasures for Sports Associations of Students in Vocational Colleges in Nanjing City.Jiangsu Education Research, 2013, (33):37-39.

[3] Wang Xiaojuan. A Study on the Position and Functions of Sports Associations in College and Universities. Journal of Jilin Institute of Physical Education , 2013,23(1):30-32.

[4] Wang Sheng. A Study on Development Status and Countermeasures for Sports Associations of Students in Vocational Colleges in Shanghai Based on Career Planning. Science and Technology Innovation Herald, 2013, (30):196-199.

[5] Fu Ming, Ren Yufeng Current Situation and Development Strategy of Sports Associations in Colleges and Universities, Journal of Mudanjiang Teachers' College (Natural Sciences Edition). 2008,(04):111-113.

[6] Wang Xueshi Tang Qiyu, On the Introduction of Market Mechanism of Sports-A Query about "Sports Can Be Industrialized instead of Marketized”. Journal of Tianjin University of Sports. 2007(03):42. 